\title{
AULA PRÁTICA DO CURSO DE ENGENHARIA ELÉTRICA NO BRASIL
}

Ana J.Ferrugem - ana.ferrugem@anhanguera.com

Faculdade Anhanguera de Campinas - Unidade 3

Rua Luiz Otávio, 1313 Bairro Taquaral

13087-018 - Campinas - São Paulo

Resumo: O aluno de graduação do curso de Engenharia Elétrica tem escassas oportunidades para aplicar o conhecimento adquirido antes de enfrentar o mercado de trabalho ou iniciar sua pós-graduação. A aula prática é uma dessas oportunidades. Este artigo mostra um breve panorama do ensino de engenharia elétrica no que tange as aulas práticas nas instituições de ensino superior no Brasil. Além do contexto brasileiro, com algumas mudanças e impactos na carga horária do curso, será descrito como as aulas de laboratórios são expostas nas matrizes curriculares e quais as vantagens e desvantagens de cada definição apresentada. Os tipos de aula prática evidenciam a forma como os alunos as percebem e como cada uma atinge um nível de profundidade na construção do conhecimento. A organização da aula de laboratórios com suas etapas e desafios, também será abordado nesse trabalho.

Palavras-chave: Laboratório Engenharia Elétrica. Aula Prática Engenharia elétrica. Experimentos Engenharia Elétrica.

\section{INTRODUÇÃO}

O grande objetivo das instituições de ensino superior é a formação discente qualificada, bons profissionais e pesquisadores, ou seja, mão de obra preparada para o mercado de trabalho e para a evolução da tecnologia e progresso da ciência no meio acadêmico. O curso de engenharia elétrica, em permanente evolução tecnológica, é um grande desafio. Há a preocupação de constante atualização das matrizes curriculares, geralmente voltada para competências que os alunos deverão adquirir durante o curso como solução de problemas, inovação e criatividade. $\mathrm{O}$ uso do laboratório no curso de engenharia elétrica aproxima a realidade em um ambiente controlado confirmando os assuntos trabalhados na aula teórica. Mas, também, auxilia na criação dessas competências. Para a instituição é, às vezes, custoso manter um laboratório, pois é necessário contratar profissionais técnicos dedicados para supervisão e manutenção do espaço.

Neste artigo, será abordado o contexto brasileiro da aula prática no curso de engenharia elétrica, como ela é discriminada na matriz curricular, os tipos e a organização adotada. Grande parte desse conhecimento vem da experiência prática da autora como professora no curso de engenharia elétrica e ex-coordenadora do curso de engenharia de produção na Faculdade Anhanguera de Campinas (FAC3).

\section{CONTEXTO BRASILEIRO}


Os registros oficiais afirmam que há cerca de 100.000 estudantes matriculados por ano nos 571 cursos de Engenharia Elétrica no Brasil (INEP, 2019). A IES (Instituição de Educação Superior) "é uma unidade de organização institucional no âmbito do ensino superior, pública ou privada, e que pode ser universidade, centro universitário, faculdade, instituto ou escola" conforme glossário na página oficial do Lattes (2020). Há certa autonomia dada pelo Ministério da Educação (MEC) para as IES na gestão e alteração das matrizes curriculares que discriminam a carga horária teórica e prática do curso. As matrizes curriculares desses cursos, das 428 instituições existentes, são organizadas, basicamente, em disciplinas obrigatórias, eletivas, atividades complementares e estágio curricular com carga horária compatível ao desenvolvimento do aprendizado. Quanto à carga horária total do curso, podemos dizer que "dentro da proposição do MEC - Ministério de Educação e Cultura, cogitada desde a década passada na redução das horas do Curso de Engenharia, de uma média atual de 4.500 horas para uma média de 3.200 horas" (PEKELMAN, MELO, 2004, p. 5). O impacto dessas mudanças foi uma redução significativa na teoria e também na prática do curso de Engenharia. Infelizmente não é possível fazer uma pesquisa extensa sobre a carga horária prática do curso de Engenharia Elétrica do Brasil, pois, poucas instituições mantém a matriz curricular com a carga horária detalhada em suas páginas oficiais de internet. Mas, dentre aquelas que possuem essa informação pública, normalmente, as atividades práticas do curso de engenharia elétrica no Brasil ficam em torno de $20 \%$ da carga horária total do curso. Adicionalmente, o MEC durante as visitas que realiza periodicamente nas IES; seja para credenciamento, recredenciamento, reconhecimento ou autorização; sempre reafirma a importância dos laboratórios. Para a instituição é importante ter um bom ambiente para as práticas laboratoriais, pois também, é uma exigência ou desejo da maior parte dos alunos da engenharia a utilização desse espaço.

Durante o curso de engenharia elétrica existem as disciplinas que são preliminares para a assimilação dos conteúdos técnicos. Conforme a Resolução CNE/CES n ${ }^{0}$. 11, de 11 de março de 2002, o curso é dividido em 3 núcleos: básico, profissionalizante e específico. As disciplinas do núcleo básico, comuns a todas engenharias; são: matemática, informática, desenho técnico, estatística, física, química e humanas. Elas representam 30\% da carga horária do curso. Dentre as disciplinas citadas anteriormente, as que tem aula prática comumente são: física, química, informática e desenho técnico. As disciplinas do curso do núcleo profissionalizante contemplam cerca de $15 \%$ da carga horária do curso. Elas, a partir desse ponto no curso, já realizam a divisão dos alunos, conforme a modalidade da engenharia e são definidas conforme a IES. O núcleo específico aprofunda o núcleo profissionalizante e finaliza o restante da carga horária do curso de engenharia elétrica e representa cerca de 55\% (DIAS, 2016). Esses dois últimos núcleos têm de maneira geral as seguintes disciplinas: eletricidade, circuitos, eletrônica, motores, eletrônica de potência, instrumentação, microprocessadores, telecomunicações e automação. Evidente que, muitas dessas disciplinas, são ofertadas dependendo da ênfase do curso. Isso também é um princípio norteador para aulas práticas quanto ao nível de profundidade.

\section{AULA PRÁTICA NO CURSO DE ENGENHARIA ELÉTRICA}

A aula prática é um espaço e processo de interação do aluno com atividades que se aproximam, simulam o seu dia-a-dia ou demostram conceitos no mundo real. É onde se faz um reforço ou complemento do que foi visto na aula teórica. Os objetivos são diversos:

- Desenvolver no estudante sua capacidade de observação; 
- Criar situações em que o estudante possa verificar uma relação entre o que foi aprendido em sala de aula e o experimento em si através de sua análise;

- Compreensão do sistema apresentado que leva ao aprendizado;

- Conseguir expressar através de uma forma clara, lógica e bem estruturada o que foi aprendido através da elaboração de relatórios;

- Adquirir conhecimento para solucionar futuros problemas similares através de experimentos laboratoriais, softwares ou instrumentos matemáticos adequados.

Vale também lembrar que as diretrizes nacionais para o curso de engenharia integrantes no CNE/CES n. ${ }^{\circ}$ 1.362/2001 (2002, p. 04 ressalta as competências e habilidades: "projetar $e$ conduzir experimentos e interpretar resultados; identificar, formular e resolver problemas de engenharia". Ou seja, é exigido do aluno egresso essas habilidades. Os laboratórios, durante as aulas práticas ou fora delas, devem ser usados para fins didáticos e também exploratórios com fim de preparar os alunos para em um futuro a fim de prover a inovação tecnológica através do aprendizado da criatividade segundo Pekelman e Mello (2004).

Os equipamentos utilizados, basicamente em todos os laboratórios de engenharia elétrica, são: osciloscópios, multímetros, gerador de funções e fontes de tensão. Há também os laboratórios de informática, ou simplesmente laboratórios virtuais, onde normalmente se tem os softwares de apoio como Matlab, MathCAD e Multsim, que dependem de uso de licença comprada pela instituição. Neles, é possível realizar cálculos, construir gráficos, elaborar rotinas computacionais, realizar simulação de eletromagnetismo e de circuitos elétricos. A utilização desses tipos de softwares auxilia o desenvolvimento e a construção de projetos em protoboard ou placas eletrônicas. Também se usa vários tipos de kits comprados de empresas especializadas em educação superior no que tange ensino tecnológico e científico. Eles abrangem normalmente aulas práticas de eletromagnetismo, motores, montagens de pequenos robôs, plataforma Arduino, CLP ou outras práticas. Os kits concentram peças que se montadas e/ou rearranjadas tornam o experimento lúdico e diversificado. Tanto os kits, como os laboratórios virtuais, principalmente esse último; facilitam a organização por parte do professor e o acompanhamento do conteúdo pelos alunos facilitando o ensino-aprendizagem (MACEDO, 2012).

Conforme Pekelman e Mello (2004) é preciso também incentivar o uso do laboratório por parte dos alunos fora do horário da aula prática. Isso encoraja a pesquisa e a curiosidade com a realização de pequenas experiências.

\section{AULA PRÁTICA NA MATRIZ CURRICULAR}

As IES no Brasil discriminam as aulas práticas de duas formas nas suas matrizes curriculares: aula prática como disciplina isolada e aula prática e teórica como disciplina única. Há autonomia por parte da instituição de qual forma apresentar. As duas formas de apresentação na matriz curricular podem ter vantagens e desvantagens.

\subsection{Aula prática como disciplina isolada}

A aula prática é uma disciplina com carga horária específica oferecida normalmente no mesmo semestre da disciplina teórica correlacionada complementando-a. O professor pode ser o mesmo para as duas disciplinas (prática e teórica) ou não.

\section{Vantagens}

Para o aluno, a carga horária prática realizada no curso se torna clara. $\mathrm{O}$ fato de ter a carga horária determinada de uma forma tão explícita para o corpo docente e discente faz com que se 
tenha um esforço adicional para cumpri-la rigorosamente. Há uma tendência de elevar o grau de excelência e ainda mais quando se tem um professor dedicado a esse fim.

\section{Desvantagens}

Como desvantagem, para o caso de ser dois professores, há a possibilidade de ocorrer falta de sinergia entre os dois docentes que pode afetar a não correlação entre prática e teoria. Há também a chance das duas disciplinas (teórica e prática) serem desconectadas temporalmente. Isso prejudicaria o aprendizado dos alunos que, idealmente, para aproveitar os conhecimentos no processo de aprendizagem devem ter contato a priori com a teoria e após com a prática.

\subsection{Aula prática e teórica como disciplina única}

A aula prática é uma complementação da teoria e ambas são somente uma disciplina. A carga horária da aula prática não é tão evidente para os discentes e docentes como no primeiro caso. $\mathrm{O}$ modelo em que prática e teoria são uma única disciplina normalmente utiliza o mesmo professor para os dois contextos diferentes.

\section{Vantagens:}

Há vantagem da possível integração total das duas sem perigo da desconexão temporal. O professor acompanha os alunos em ambas atividades. As habilidades e dificuldades de cada estudante se torna evidente para o docente que poderá o avaliar nesses dois âmbitos com mais propriedade.

\section{Desvantagens:}

Uma desvantagem é que o professor frente a uma carga teórica extensa, que é absolutamente habitual para o curso de engenharia elétrica, e muitas vezes, associada à dificuldade de assimilação do conteúdo por parte dos alunos, tende a reforçar em sala de aula conceitos e exercícios e com isso reduz o tempo para o uso do laboratório. Com uma carga horária limitada, os professores, na maioria das vezes, tendem a escolher entre ministrar a teoria na totalidade, em detrimento das aulas práticas. Isso é perfeitamente compreensível, pois a teoria é cobrada nas provas e no ENADE (Exame Nacional de Cursos).

\section{TIPOS DE AULA PRÁTICA}

Deixando de lado como a aula prática é apresentada na matriz curricular dos cursos, podemos analisar a forma como são feitas as aulas práticas no curso de engenharia elétrica. Basicamente existem três tipos de abordagem de aula de laboratório no curso.

\subsection{Aula prática expositiva}

O professor faz antecipadamente o experimento e exibe aos alunos como forma demonstrativa. Cabe aos alunos, com direcionamento do docente, contextualizar o experimento com os conhecimentos teóricos até então adquiridos. A justificativa para utilizar esse padrão pode ser pelo fato do experimento ser dispendioso, perigoso ou envolvendo grande área do laboratório inviabilizando tornar a experiência factível pelos alunos. Esse tipo de aula prática é usada, por exemplo, para experiências mais complexas envolvendo eletromagnetismo ou tensões elétricas consideradas altas. Também pode ser adotado, caso a instituição não tenha fisicamente kits práticos para utilização de muitos grupos. Raras vezes é solicitado um relatório ou trabalho frente a observação dos alunos da aula prática expositiva. Geralmente ela tem um caráter apenas de observação. 


\subsection{Aula prática com roteiro}

Este é um dos modelos mais utilizados onde em pequenos grupos, duplas ou até individualmente, a experiência é feita pelos alunos passo a passo, seguindo um roteiro criado pelo professor ou pela instituição. Na maioria das vezes é solicitado um relatório e não poucas vezes, o resultado é pífio. O professor precisa deixar claro como deseja o formato desse documento, pois os alunos confundem o roteiro da prática com a forma solicitada que deve ser entregue. $\mathrm{O}$ aluno que não é proativo é amparado e conduzido por esse sistema com mais segurança durante a prática. Em contrapartida, seria interessante tornar esse momento mais investigativo, e não apenas didático, para fomentar o protagonismo dos alunos contribuindo para o desenvolvimento dessas habilidades. Para tanto, as perguntas dos roteiros deveriam necessariamente ser mais abertas, o que exige maior maturidade da turma que realiza a prática. (ANDRADE, DINIZ, CAMPOS, 2011).

\subsection{Aula prática por projetos}

Promover novas metodologias com autonomia do aluno incentivando o seu protagonismo (Zimmermann, 2018) é um dos objetivos na formação do engenheiro eletricista. Os dois primeiros métodos priorizam a transmissão de conhecimento com o seu devido valor e importância em todo o processo. A aula prática por projetos incentiva a criatividade, inovação, análise e a construção de um produto por parte do aluno. É um trabalho em grupo diferenciado onde a participação é mais exigente do que nos roteiros tipo "receita" (ANDRADE, DINIZ, CAMPOS, 2011). O professor propõe a divisão em pequenos grupos a escolha dos projetos em sala de aula. Os alunos se organizam e necessitam criar requisitos (se não for determinado pelo docente) e trabalhar durante o semestre no desenvolvimento do experimento. Eles usam o tempo total da aula prática para produzir o seu projeto. No final da disciplina geralmente é realizada uma apresentação para os colegas e professor.

Esse tipo de aula prática tem sentido se realizada nos últimos semestres do curso onde é sedimentado tudo que foi visto até então. Há uma interação mais estreita entre os colegas do grupo devido ao tempo e a complexidade do experimento. O suporte do professor é mais exigente e desafiador devido a multiplicidade e diferenciação de trabalhos.

\section{ORGANIZAÇÃO DA AULA PRÁTICA}

A aula prática é um dos pontos altos para o aprendizado de uma grande parte dos alunos. Por isso, a organização é de suma importância com atividades anteriores e posteriores à realização do experimento.

\subsection{Pré-Aula de Laboratório}

Antes da aula de laboratório, durante a aula teórica, o professor prepara os alunos sobre os futuros experimentos que ocorrerão. Primeiramente explanando claramente a teoria que será usada na prática. Em segundo, normalmente, fazendo uma pequena chamada para a aula prática buscando despertar o interesse e envolvimento dos alunos.

\subsection{Aula de Laboratório}


O professor no início da aula prática, para melhor aproveitamento e condução do experimento, frequentemente retoma a teoria apresentada na sala de aula, realizando conexão com o experimento a ser feito. Isso situa os alunos e também contorna a ausência de alguns alunos da aula teórica, e, portanto, com o possível desconhecimento, no conteúdo a ser visto. Novamente, os alunos são instigados a realizar os experimentos com curiosidade e motivação. Um detalhe importante a ser abordado é que os alunos investem muito tempo no manuseio dos equipamentos para realizar as medidas. Isso é feito de maneira mecânica e infelizmente há pouco tempo para a análise dos resultados. Um nivelamento no início do semestre no manuseio dos equipamentos torna o uso mais familiar. (ANDRADE, DINIZ, CAMPOS, 2011). Outra observação importante é que para os roteiros tipo "receita" quanto mais abertos, com o problema bem definido, mas não detalhado, melhor para os alunos construírem a experiência e também sua formação como protagonista na solução de problemas e no seu próprio desenvolvimento. Importante lembrar que a experiência deve estar no nível da disciplina teórica para permitir ao aluno um bom acompanhamento. Se o roteiro estiver aberto e mal definido, pode induzir o aluno a percorrer outro caminho e não chegar a conclusão desejada. É importante que o professor acompanhe o andamento das experiências não respondendo todas as perguntas, mas criando situações que o aluno consiga responder por si mesmo.

\subsection{Pós-Aula de Laboratório}

Para sedimentar o conhecimento é necessário que os alunos possam registrar suas descobertas de maneira ordenada após tomar suas conclusões. Normalmente os alunos não gostam de registrar e que é muito comum para o perfil discente da engenharia. No meio profissional, existe em fábricas e empresas também essa necessidade e, portanto, é preciso criar essa competência nos estudantes. Se o aluno for para o meio acadêmico, a construção desses documentos pode ajudar na construção do conhecimento para publicações futuras em geral. Estes documentos são produtos da pós aula de laboratório. Eles podem ser fichas de perguntas que aguardam respostas intuitivas e conclusivas. Elas direcionam para uma lógica de aprendizagem e normalmente são entregues no final da aula para a avaliação do professor.

Também são usados, e até mais frequentemente, a redação de relatórios. Esses relatórios são criados com roteiro simples: introdução, desenvolvimento e conclusão e até mais elaborados seguindo a norma da ABNT ou de artigos científicos. Enfim, é permitida no curso de engenharia todo o tipo de relatório: dos que tem redação livre aos mais elaborados. Não há uma uniformidade dos professores que ministram aulas de laboratório quanto a esse documento entregue no final do semestre ou no após cada experiência. Muitas vezes, a disciplina de Metodologia Científica; ministrada em muitos cursos de engenharia, inclusive no curso de engenharia elétrica, no núcleo básico; não é utilizada nos relatórios e trabalhos do próprio curso. Geralmente, os documentos entregues são parte da nota do semestre ou se for a aula prática como disciplina isolada, nota poderá ser na totalidade dependente desses relatórios entregues.

\section{CONSIDERAÇÕES FINAIS}

Os alunos em geral gostam das aulas de laboratório e se sentem motivados em fazê-las. Há um certo pesar da parte deles quando a experiência não tem sucesso, os equipamentos estão sem calibração e falhas, as turmas são grandes prejudicando o aproveitamento, ou há poucas aulas práticas durante o curso. Existe uma grande responsabilidade na entrega de aulas práticas de qualidade por parte das IES do Brasil. Vimos que no Brasil há uma diversidade muito grande de condução das aulas de laboratório, seja devido a matriz curricular escolhida pela instituição, 
o tipo de aula prática, a organização do laboratório e os documentos entregues após as práticas. Essa diversidade ou falta de uniformidade implica identidade da própria instituição quanto as práticas do curso de Engenharia Elétrica. Cabe ao coordenador do curso e o corpo docente, preferencialmente o NDE (Núcleo Docente Estruturante) buscar que os laboratórios e metodologia de aula prática estejam em franca atualização conforme as necessidades de mercado e contexto tecnológico.

Esse trabalho, longe de ser conclusivo, é o início de uma pesquisa que a autora pretende fazer sobre as aulas práticas do curso de Engenharia Elétrica no Brasil. Um tema muito importante e pouco refletido.

\section{Agradecimentos}

Aos amigos Marcelo Tavares de Lima e Amanda Costa Martinez pela preciosa ajuda com dicas e encorajamento.

\section{REFERÊNCIAS:}

ANDRADE, A. C. DE; DINIZ, L. G.; CAMPOS, J. C. C. Uma metodologia de ensino para disciplinas de laboratório didático. Revista Docência do Ensino Superior, v. 1, p. 128-144, 15 out. 2011.

BRASIL. Resolução CNE/CES no. 11, de 11 de março de 2002. Diretrizes Curriculares Nacionais do Curso de Graduação em Engenharia. MEC-CNE-CES. Brasília, 2002.

BRASIL. Parecer CNE/CES n. ${ }^{\circ}$ 1.362/2001. Despacho do ministro em 22/2/2002, publicado no diário oficial da união de 25/2/2002, Seção 1, p. 17.

DIAS, Renata Rampim de Freitas et al. Identificação por radiofrequência: uma ferramenta de ensino. 36f.Tese(Doutorado) - Faculdade de Engenharia Elétrica e Computação, Universidade Estadual de Campinas, Campinas, 2016.

GLOSSÁRIO Diretórios dos grupos de pesquisa no Brasil. Disponível em: http://lattes.cnpq.br/web/dgp/glossario. Acesso em 29 jul. 2020

INSTITUTO NACIONAL DE ESTUDOS E PESQUISAS EDUCACIONAIS ANÍSIO TEIXEIRA. Sinopse Estatística da Educação Superior 2018. Brasília: Inep, 2019. Disponível em: http://portal.Inep.gov.br/basica-centro-escolar-sinopse-sinopse. Acesso em 29 jul. 2020

MACEDO, Renata J.; DUARTE, Marcelo de A.; TEIXEIRA, Nelson G. Novas metodologias de ensino e aprendizagem aplicadas ao curso de Engenharia Elétrica: o foco do ensino no século XXI. In: XL Congresso Brasileiro de Educação em Engenharia, Belém. 2012.

PEKELMAN, Helio; MELLO, Jr AG. A importância dos laboratórios no ensino de engenharia mecânica. In: Anais do XXXII Congresso Brasileiro de Ensino de EngenhariaCOBENGE. Brasília, 2004.

ZIMMERMANN, Ana Carolina. Proposição de ambiente de aprendizagem ativa: Laboratório Aberto de Brasília. 2018. 155 f., il. Trabalho de Conclusão de Curso (Bacharelado em 
Engenharia de Produção)—Universidade de Brasília, Brasília, 2018.

\begin{abstract}
The graduate student of the Electrical Engineering course has few opportunities to apply the knowledge acquired before facing the job market or starting his postgraduate course. The practical class is one of those opportunities. This article shows a small overview of the teaching of electrical engineering with regard to practical classes in higher education institutions in Brazil. In addition to the Brazilian context, with some changes and impacts on the course load, we will describe how laboratory classes are exposed in the curriculum matrices and what are the advantages and disadvantages of each definition presented. The types of practical classes show how students perceive them and how each one reaches a level of depth in the construction of knowledge. The organization of the laboratory class with its stages and challenges, will also be addressed in this work.
\end{abstract}

Keywords: Electrical Engineering Laboratory. Practical Lesson Electrical engineering. Electrical Engineering Experiments. 